\title{
Accuracy of in-house alcohol-dissolved wheat extract for diagnosing IgE-mediated wheat allergy
}

\author{
Punchama Pacharn, ${ }^{1}$ Nunthana Siripipattanamongkol, ${ }^{1}$ Nittida Pannakapitak, ${ }^{1}$ Nualanong Visitsunthorn, ${ }^{1}$ \\ Orathai Jirapongsananuruk, ${ }^{1}$ Surapon Piboonpocanun, ${ }^{2}$ Pakit Vichyanond ${ }^{3}$
}

\begin{abstract}
Background: The standard method for diagnosing immediate wheat allergy is oral food challenge test (OFC). However, OFC can provoke anaphylaxis during the challenge process. Skin prick test (SPT) using commercial wheat extract yielded unsatisfactory result for diagnosis of wheat allergy. As a result, an in-house, alcohol-dissolved (Coca-10\% EtOH) wheat extract was developed to improve accuracy of the SPT.
\end{abstract}

Objective: To determine the accuracy of in-house, alcohol-dissolved wheat extract in children with immediate wheat allergy

Methods: This prospective cross-sectional study included children with history of immediate reaction after wheat ingestion. SPTs with commercial and in-house Coca-10\% EtOH wheat extract were performed and wheat and omega-5 ( $\omega-5)$ gliadin specific IgE (sIgE) were measured. Patients with no history of recent anaphylaxis after wheat ingestion underwent OFC with 31 grams of wheat flour.

Results: Thirty children were recruited. Thirteen of those had history of anaphylaxis after wheat ingestion. Eleven of the remaining 17 children (64.7\%) had a positive result for wheat challenge test. Wheal size of $3 \mathrm{~mm}$ for both in-house and commercial wheat extract yielded the best accuracy for the test. Using these cutoff parameters, in-house Coca- $10 \% \mathrm{EtOH}$ wheat extract yielded $91.7 \%$ sensitivity, $66.7 \%$ specificity, and $86.7 \%$ accuracy. Comparatively, the commercial extract yielded $70.8 \%$ sensitivity, $100 \%$ specificity, and $76.6 \%$ accuracy.

Conclusion: SPT using in-house Coca-10\% EtOH wheat extract yielded better accuracy than commercial extract for diagnosing immediate type wheat allergy in children.

Key words: accuracy, gliadin, diagnosis, wheat allergy, wheat extract

From:

${ }^{1}$ Division of Allergy and Immunology, Department of Pediatrics, Faculty of Medicine Siriraj Hospital, Mahidol University, Bangkok, Thailand

2 Institute of Molecular Biosciences, Mahidol University,

Salaya Campus, Nakhonpathom, Thailand

${ }^{3}$ Samitivej Allergy Institute, Samitivej Thonburi Hospital, Thonburi, Bangkok, Thailand

\section{Introduction}

Food allergy is common in children. The vast majority of food allergic reactions are due to milk, egg, peanut, soy, and wheat. ${ }^{1-3}$ Among these foods, wheat is a common ingredient in many foods that are widely consumed around the world. From the EuroPrevall meta-analysis of $2008,{ }^{4}$ prevalence of wheat allergy by oral food challenge (OFC) and skin prick test (SPT) was approximately $0.5 \%$. According to our review of the literature, no previous data regarding the prevalence of wheat

\section{Corresponding author:}

Punchama Pacharn

Division of Allergy and Immunology, Department of Pediatrics

Faculty of Medicine Siriraj Hospital, Mahidol University

2 Prannok Road, Bangkoknoi, Bangkok 10700, Thailand

E-mail: punchama@gmail.com

allergy was reported from Thailand. The potential of wheat to cause disease is a matter of concern, especially with regard to severity. Most patients who are allergic to wheat present with anaphylaxis, especially in Asia. ${ }^{5}$

Double-blinded placebo-controlled food challenge test is a standard procedure used to diagnose wheat allergy. In children, the open challenge test was also shown to be reliable. ${ }^{6}$ However, both procedures are limited by the associated risk of 
anaphylaxis. Other diagnostic methods, such as SPT or measuring specific IgE (sIgE) level to wheat, revealed unsatisfactory results. $^{7}$

Wheat protein can be classified into either water/salt-soluble albumins and globulins or water/salt-insoluble gliadins and glutenins. ${ }^{8}$ Omega-5 gliadin ( $\omega-5$ gliadin) and high molecular weight (HMW) glutenin were identified as the major allergens for IgE-mediated wheat allergy and wheat-dependent exercise-induced anaphylaxis (WDEIA)..$^{9,10}$ As a result, level of $\omega-5$ gliadin sIgE showed better diagnostic capacity than level of wheat $\operatorname{sigE.}{ }^{11,12}$

Testing of $\omega-5$ gliadin sIgE level is expensive and not globally available, most notably in developing countries. In addition, it cannot detected patients who did not allergic to $\omega-5$ gliadin. Our previous study showed that in-house Coca-10\% EtOH solution could extract both water/salt and alcohol soluble wheat allergens in one extraction process. ${ }^{13}$ The aim of this study was to determine the accuracy of in-house Coca-10\% $\mathrm{EtOH}$ wheat extract in children with immediate wheat allergy.

\section{Methods \\ Study population}

The protocol for this study was approved by the Siriraj Institutional Review Board (SIRB), Faculty of Medicine Siriraj Hospital. Mahidol University. This prospective cross-sectional study was conducted in patients aged 1-15 years with a history of immediate wheat hypersensitivity who attended the Pediatric Allergy Clinic at Siriraj Hospital during the 2009 to 2012 study period. Siriraj Hospital is Thailand's largest universitybased national tertiary referral center. Written informed consent from parents or guardians and assent from children older than 7 years of age were obtained prior to inclusion. Patients with underlying diseases, such as cardiovascular (CVS), hepatobiliary, and renal diseases, were excluded. Treatment with antihistamines and glucocorticoids was suspended for at least 7 days prior to OFC.

\section{Preparation of Coca-10\% EtOH wheat extract}

Coca-10\% EtOH wheat extract was prepared as described in a previous report. ${ }^{13}$ Briefly, whole wheat flour was dissolved in Coca's solution $(29.8 \mathrm{mM} \mathrm{NaHCO}, 86 \mathrm{mM} \mathrm{NaCl}$, and 42.5 $\mathrm{mM}$ phenol) containing $10 \% \mathrm{v} / \mathrm{v}$ absolute ethanol under laminar air flow and using sterile technique. The solution was magnetically stirred for 1 hour at room temperature. It was then centrifuged at $17,210 \times \mathrm{g}$ for 10 minutes before being sterile filtered through a 0.2 micron filter. The extract was stored at $4^{\circ} \mathrm{C}$ with a usable shelf life of 3 months.

\section{Skin testing and specific IgE}

All subjects underwent SPT with the commercial wheat extract (ALK-Abelló A/S, Hørsholm, Denmark) and our inhouse Coca-10\% EtOH wheat extract. SPT was performed by a technician who was blinded to the extract group. SPT was performed on the volar aspect of the forearm with a monodentate lancet. Histamine dihydrochloride $(10 \mathrm{mg} / \mathrm{mL})$ was used as a positive control, with normal saline used as a negative control. A result was considered positive if the wheal size had a mean diameter of at least $3 \mathrm{~mm}$. All patients were tested for wheat and $\omega-5$ gliadin specific IgE antibodies using ImmunoCAP specific IgE test (Phadia Laboratory Systems, Uppsala, Sweden) (lower detection limit $<0.35 \mathrm{kAU} / \mathrm{L}$ ).

\section{Oral food challenge test}

Open oral food challenge test with 31 grams of wheat (2 slices of bread) was performed in all patients who had no recent history of anaphylaxis to wheat. The provocation dose (PD) schedule of wheat was, as follows: $100 \mathrm{mg}, 500 \mathrm{mg}, 1,2,4$, 8 , and 15.4 grams at 30 -minute intervals. Before administering the test meal, the oral cavity and skin were carefully inspected for pre-existing lesions and baseline blood pressure level was measured.

Vital signs and patient signs and symptoms were recorded every 15 minutes. Emergency resuscitation equipment and medicines were available in case of anaphylaxis. Anaphylaxis was diagnosed using National Institute of Allergy and Infectious Disease/Food Allergy and Anaphylaxis Network symposium criteria. ${ }^{14}$ Intravenous access was obtained and maintained for all patients during OFC.

\section{Data collection and analysis}

Data analysis was performed using PASW Statistics version 18.0 (SPSS, Inc., Chicago, IL, USA). Demographic and clinical characteristics data are presented as median (range) for continuous data and as number (percentage) for categorical data. Comparisons median of MWD from skin tests between groups of positive and negative challenges were made using MannWhitney $U$ test. Differences between groups were considered to be significant at a $p$-value of $\leq 0.05$.

\section{Results \\ Patient characteristics}

Thirty subjects (18 boys and 12 girls) with history of immediate hypersensitivity to wheat were recruited. Thirteen had history of anaphylaxis after wheat ingestion. Baseline characteristics of participants are shown in Table 1. Median age at onset was 9 months (range: 4-84). Median age at solid food introduction was 6 months (range: $3-8$ ). Ten patients $(33.3 \%)$ had personal history of atopy and only 5 of those patients had history of atopic dermatitis.

Table1. Demographic data of the study population $(\mathrm{N}=30)$

\begin{tabular}{lc} 
Characteristics & \\
\hline Age at onset (months), median (range) & $9(4-84)$ \\
Age at oral challenge test (months), median (range) & $33(15-156)$ \\
Boys, n (\%) & $18(60.0)$ \\
Severity of symptoms, n (\%) & $17(56.6)$ \\
Wheat allergy & $13(43.3)$ \\
Wheat anaphylaxis & $10(33.3)$ \\
Personal history of atopy, n (\%) & $6(20.0)$ \\
Allergic rhinitis & $5(16.7)$ \\
Atopic dermatitis & $3(10.0)$ \\
\hline Asthma
\end{tabular}


Table1. (Continued)

\begin{tabular}{ll} 
Characteristics & \\
History of hypersensitivity to other foods, $\mathrm{n}(\%)$ & $10(33.3)$ \\
Egg whites & $6(20.0)$ \\
Cow's milk & $5(16.7)$ \\
Egg yolk & $3(10.0)$ \\
Soy bean & $3(10.0)$ \\
Seafood & $1(3.3)$ \\
Peanut & $16(53.0)$ \\
Family history of atopy, $\mathrm{n}(\%)$ & $7(23.0)$ \\
Mother & $9(30.0)$ \\
\hline Father &
\end{tabular}

\section{Challenge test results}

Of the 17 children who underwent oral wheat challenge (OWC), 6 children (35.3\%) had negative result and 11 children $(64.7 \%)$ had positive result. Two of 11 patients developed anaphylaxis during OWC. Thirteen children were not challenged due to their recent history of anaphylaxis. Thus, a total of 15 children were classified as wheat anaphylaxis. The results of patient flow through the study are shown in Figure 1. When comparing patients with negative OWC with those who had positive OWC or anaphylaxis, there were no differences for gender, age at onset, age at solid food introduction, or history of other food allergy (Table 2). Personal and family history of atopy were higher in the anaphylaxis group than in the other groups, but the differences were not statistically significant. Symptoms of wheat hypersensitivity are shown in Table 3. Gastrointestinal symptoms included nausea, vomiting, and acute diarrhea.
Table 2. Clinical characteristic among different group of wheat allergic patients.

\begin{tabular}{lcccc} 
& & \multicolumn{3}{c}{ Final diagnosis } \\
\cline { 3 - 5 } $\begin{array}{l}\text { Patient } \\
\text { characteristics }\end{array}$ & $\begin{array}{c}\text { All } \\
\text { patients }\end{array}$ & Anaphylaxis & $\begin{array}{c}\text { Positive } \\
\text { wheat } \\
\text { challenge }\end{array}$ & $\begin{array}{c}\text { Negative } \\
\text { wheat } \\
\text { challenge }\end{array}$ \\
\hline $\begin{array}{l}\text { Total number } \\
\text { Gender, }\end{array}$ & 30 & 15 & 9 & 6 \\
$\begin{array}{l}\text { male/female } \\
\begin{array}{l}\text { Age at onset } \\
\text { (month), }\end{array}\end{array}$ & $18 / 12$ & $9 / 6$ & $6 / 3$ & $3 / 3$ \\
median (range) & $(4-84)$ & $(5-84)$ & $(4-44)$ & $(6-60)$ \\
$\begin{array}{l}\text { Age at wheat } \\
\text { challenge } \\
\text { (month), }\end{array}$ & & & & \\
median (range) & $(15-156)$ & $(22-35)$ & $(15-156)$ & $(16-120)$ \\
\hline
\end{tabular}

Age at solid food

$\begin{array}{lcccc}\text { introduction } & 6 & 6 & 6 & 6 \\ \text { (month), } & (3-8) & (3-8) & (4-8) & (4-6) \\ \text { median (range) } & & & & \end{array}$

$\begin{array}{lllll}\begin{array}{l}\text { Other food } \\ \text { allergies }\end{array} & 14 & 6 & 5 & 3\end{array}$

$\begin{array}{lllll}\begin{array}{l}\text { Family history } \\ \text { of atopy }\end{array} & 13 & 8 & 4 & 1\end{array}$

Personal history

of atopy

$\begin{array}{lllll}\text { - Asthma } & 3 & 3 & 0 & 0 \\ \text { - Allergic } & 6 & 5 & 1 & 0 \\ \text { rhinitis } & 5 & 2 & 1 & 2 \\ \text { - Atopic } \\ \text { dermatitis }\end{array}$

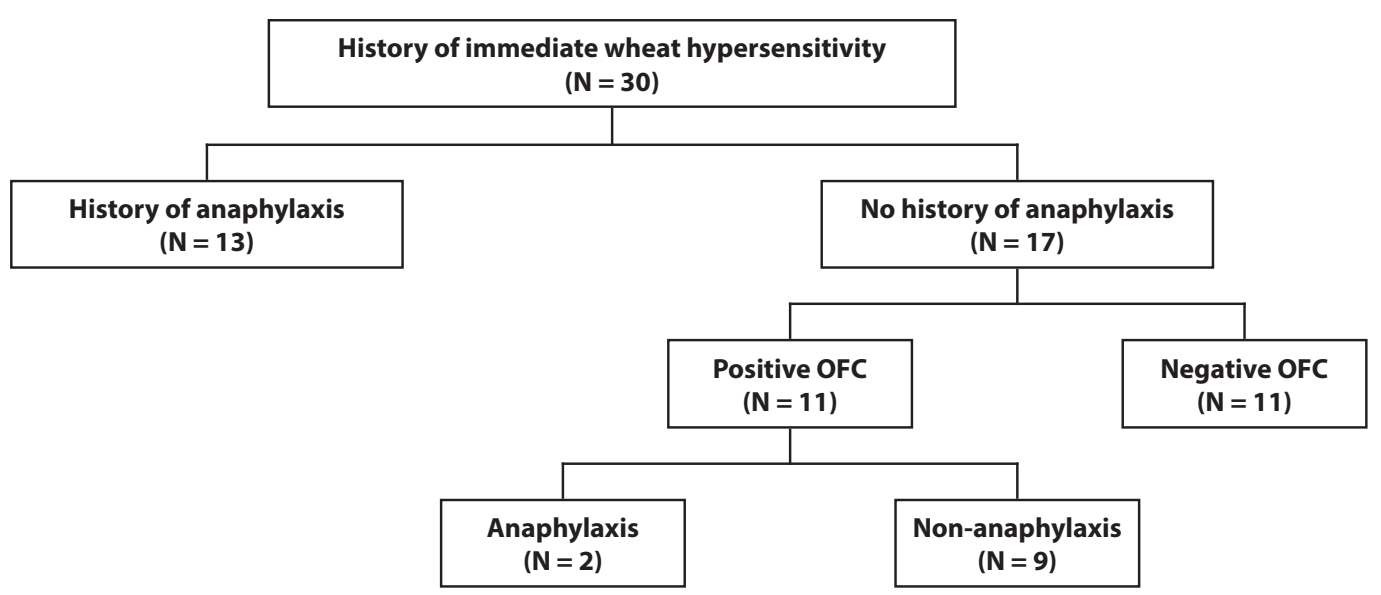

Figure 1. Flow chart of patient recruitment and wheat challenge outcome 
Table 3. Symptoms of wheat hypersensitivity $(\mathrm{N}=30)$

\begin{tabular}{|c|c|c|}
\hline & $\begin{array}{l}\text { Anaphylaxis } \\
(\mathrm{n}=15)\end{array}$ & $\begin{array}{l}\text { Positive OFC to wheat } \\
\qquad(n=9)\end{array}$ \\
\hline \multicolumn{3}{|l|}{ Skin } \\
\hline - Urticaria & 13 & 6 \\
\hline - Angioedema & 2 & 1 \\
\hline - MP rash & 0 & 1 \\
\hline \multicolumn{3}{|l|}{ Respiratory } \\
\hline - Wheeze & 9 & 0 \\
\hline - Dyspnea & 4 & 0 \\
\hline - Cough & 2 & 0 \\
\hline \multicolumn{3}{|l|}{ Gastrointestinal (GI) } \\
\hline - Vomit/diarrhea & 3 & 1 \\
\hline \multicolumn{3}{|l|}{ Neurological } \\
\hline - Unconscious & 1 & 0 \\
\hline - Seizure & 1 & 0 \\
\hline
\end{tabular}

${ }^{*}$ Anaphylaxis group: skin + respiratory $=11$; skin + respiratory $+\mathrm{GI}=2$; skin + respiratory + neurological $=1$; skin + respiratory $+\mathrm{GI}+$ neurological $=1$

Predictive diagnostic capacity of SPT, specific IgE for wheat, and specific IgE for w-5-gliadin

The sensitivity, specificity and accuracy of the various tests for predicting immediate wheat allergic reaction are shown in Table 4. Using a standard cutoff point of $3 \mathrm{~mm}$, Coca- $10 \%$ EtOH extract had higher sensitivity (91.7\% vs. $70.8 \%)$ and better accuracy $(86.7 \%$ vs. $76.6 \%)$ than commercial extract.

A

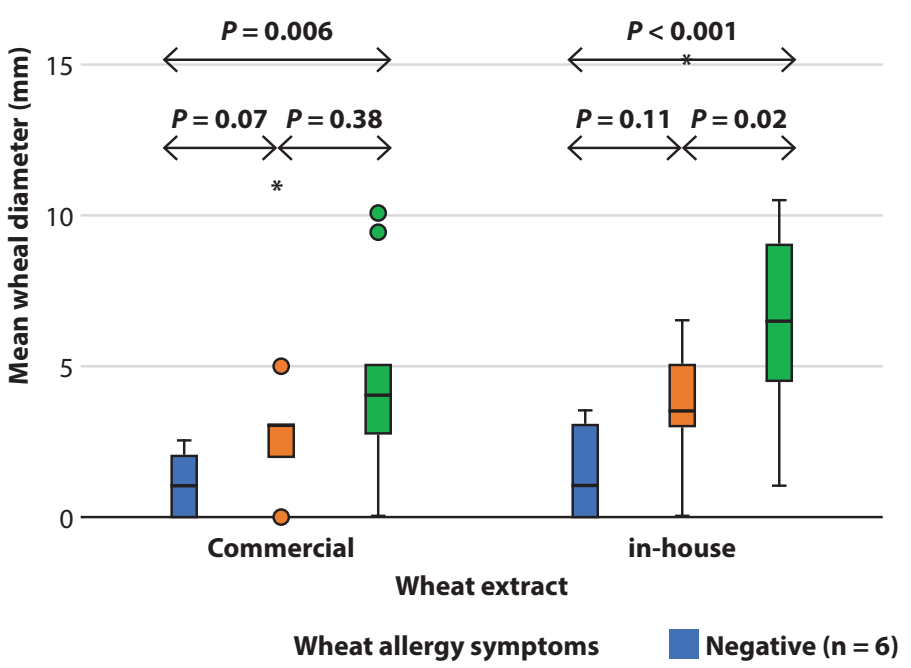

Table 4. Predictive ability of skin prick test (SPT) using commercial extract, alcohol-dissolved extract, wheat sIgE, and $\omega$-5-gliadin sIgE

\begin{tabular}{|c|c|c|c|}
\hline Test (cutoff) & $\begin{array}{l}\text { Sensitivity } \\
(\%)\end{array}$ & $\begin{array}{l}\text { Specificity } \\
(\%)\end{array}$ & $\begin{array}{c}\text { Accuracy } \\
(\%)\end{array}$ \\
\hline \multicolumn{4}{|l|}{ Skin prick test } \\
\hline $\begin{array}{l}\text { Commercial extract } \\
\text { (wheal diameter } 3 \mathrm{~mm} \text { ) }\end{array}$ & 70.8 & 100.0 & 76.6 \\
\hline $\begin{array}{l}\text { Coca-10\% EtOH extract } \\
\text { (wheal diameter } 3 \mathrm{~mm} \text { ) }\end{array}$ & 91.7 & 66.7 & 86.7 \\
\hline $\begin{array}{l}\text { Commercial + Coca-10\% } \\
\text { EtOH extract } \\
\text { (wheal diameter } 3 \mathrm{~mm} \text { ) }\end{array}$ & 91.7 & 66.7 & 86.7 \\
\hline \multicolumn{4}{|l|}{ Specific IgE } \\
\hline \multicolumn{4}{|l|}{ Wheat } \\
\hline$(0.35 \mathrm{kAU} / \mathrm{L})$ & 100.0 & 50.0 & 90.0 \\
\hline (3.5 kAU/L) & 29.2 & 83.3 & 40.0 \\
\hline (4.0 kAU/L) & 29.2 & 100.0 & 43.3 \\
\hline \multicolumn{4}{|l|}{$\omega-5$ gliadin } \\
\hline$(0.10 \mathrm{kAU} / \mathrm{L})$ & 83.3 & 83.3 & 83.3 \\
\hline$(0.35 \mathrm{kAU} / \mathrm{L})$ & 75.0 & 83.3 & 76.7 \\
\hline$(0.40 \mathrm{kAU} / \mathrm{L})$ & 50.0 & 100.0 & 60.0 \\
\hline SIgE (wheat $+\omega-5$ gliadin) & 100.0 & 33.3 & 86.7 \\
\hline
\end{tabular}

Abbreviations: PPV, positive predictive value; NPV, negative predictive value

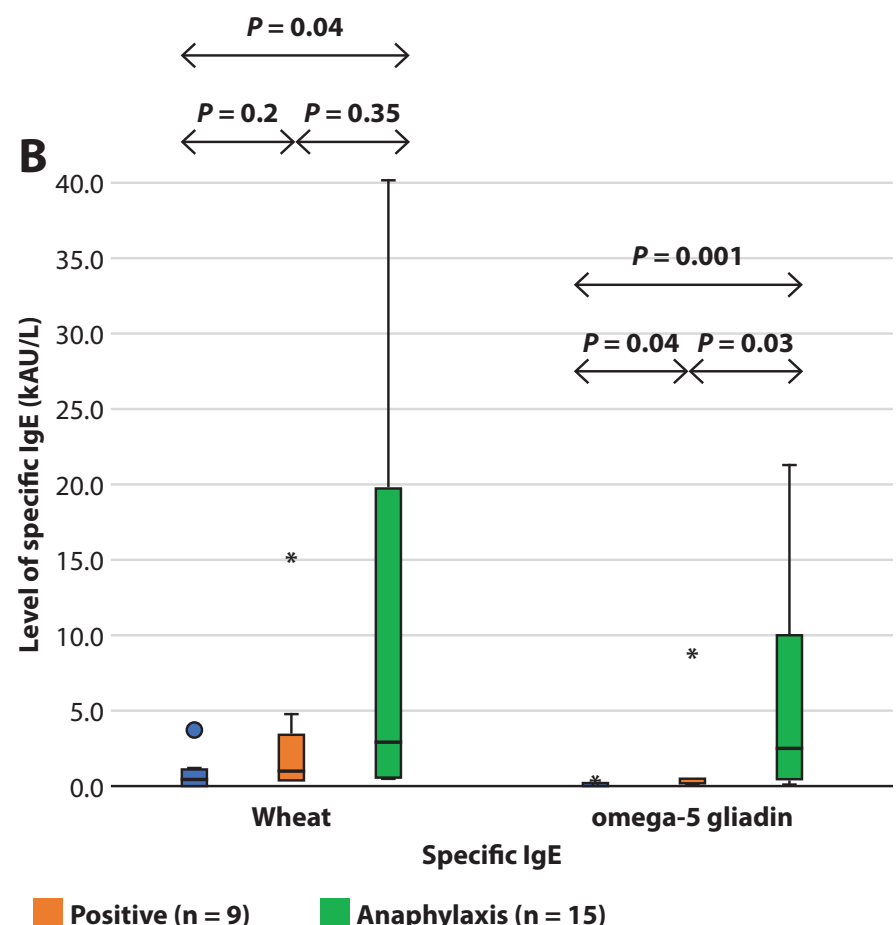

Figure 2. Comparison of patients who had negative oral wheat challenge, positive oral wheat challenge, and wheat anaphylaxis (from history and oral wheat challenge, $n=15$ )

A. Box plots of mean wheal diameter (MWD) for commercial and in-house wheat extract in patients with different wheat allergic symptoms. Comparisons median of MWD from skin tests between groups were made using Mann-Whitney U test.

B. Box plots of level of specific IgE for wheat and $\omega-5$ gliadin in patients with different wheat allergic symptoms. Comparisons median of specific IgE between groups were made using Mann-Whitney $U$ test. 
For wheat sIgE, the use of $0.35 \mathrm{kAU} / \mathrm{L}$ as a cutoff point yielded the highest sensitivity and accuracy, but only $50 \%$ specificity. At the $4 \mathrm{kAU} / \mathrm{L}$ cutoff point, specificity increased to $100 \%$, but sensitivity and accuracy decreased to $29.2 \%$ and $43.3 \%$, respectively. For $\omega-5$ gliadin $\operatorname{sIgE}$ at the $0.35 \mathrm{kAU} / \mathrm{L}$ cutoff point, specificity was $83.3 \%$ and sensitivity and accuracy were $75 \%$ and $76.7 \%$, respectively. Interestingly, the specificity increased to $100 \%$ while both sensitivity and accuracy decreased to $50 \%$ and $60 \%$, respectively, at the $0.4 \mathrm{kAU} / \mathrm{L}$ cutoff point.

Comparison of patients who had negative oral wheat challenge, positive oral wheat challenge, and wheat anaphylaxis

Mean wheal diameters from different wheat extracts in patients who had negative OWC, positive OWC, and anaphylaxis are shown in Figure 2A. Using commercial extract, the median of mean wheal diameter (MWD) in patients who had negative OWC, positive OWC, and anaphylaxis were 1, 3, and 4 $\mathrm{mm}$, respectively. Using Coca-10\% EtOH extract, those same groups had median of MWD of 1, 3.5, and $7 \mathrm{~mm}$, respectively. The size of skin prick tests from both extracts could discriminate patients who had negative OWC from patients who had anaphylaxis. However, only Coca- $10 \%$ EtOH extract could discriminate patients who had positive OWC from patients who had anaphylaxis.

Levels of sIgE to wheat and to $\omega-5$ gliadin in each group of patients are shown in Figure 2B. Mean levels of sIgE to wheat in patients with negative OWC, positive OWC, and anaphylaxis were $0.36,0.93$, and $2.86 \mathrm{kAU} / \mathrm{L}$, respectively. Median levels of sIgE to $\omega-5$ gliadin in patients with negative OWC, positive OWC, and anaphylaxis were $0.03,0.35$, and $2.46 \mathrm{kAU} / \mathrm{L}$, respectively. Both sIgE to wheat and to $\omega-5$ gliadin could discriminate patients who had negative OWC from patients who had anaphylaxis. However, only level of $\omega-5$ gliadin could discriminate negative OWC from positive OWC, and positive OWC from anaphylaxis.

\section{Discussion}

This study found that in-house Coca-10\% EtOH extract yielded higher sensitivity $(91.7 \%$ vs. $70.8 \%)$ and better accuracy $(86.7 \%$ vs. $76.6 \%)$ than ALK commercial extract for diagnosing patients with IgE-mediated wheat hypersensitivity.

There are currently no reliable testing modalities for diagnosing wheat hypersensitivity. ${ }^{15,16}$ The gold standard for testing is double-blind placebo-controlled food challenge test; however, this test is not sufficiently safe given the risk of anaphylaxis.

The diagnostic capacity of skin prick test in wheat hypersensitivity depends on the type of wheat hypersensitivity and the type of wheat extract. Several studies that set forth to determine the accuracy of skin prick test enrolled a high percentage of atopic dermatitis patients. ${ }^{10,17,18}$ As a result, good sensitivity, but poor specificity and poor positive predictive value (PPV) of skin prick test results were reported. In contrast, only $16.7 \%$ of participants had history of atopic dermatitis in our study. In this population, the use of the commercial wheat extract yielded only $70.8 \%$ sensitivity, but it was increased to $91.7 \%$ when using the in-house Coca-10\% $\mathrm{EtOH}$ extract. As such and based on these results, SPT should be considered a good choice for diagnostic testing in patients with predominant immediate wheat hypersensitivity. SPT is inexpensive, easy to perform, and available worldwide.

Wheat extracts prepared by different types of solutions have been used for diagnosis of wheat hypersensitivity. It is known that $\omega-5$ gliadin, the major allergen in IgE-mediated wheat allergy, dissolves well in alcohol. As such, water or $\mathrm{NaCl}$ solution-based wheat extracts contain lower amounts of gliadins and glutenin, which are alcohol soluble allergens. As a result, water and $\mathrm{NaCl}$ solution-based wheat extracts may not yield a high sensitivity for diagnosis. Surprisingly, studies that used either $0.9 \% \mathrm{NaCl}^{10}$ or glycerinated food extracts ${ }^{19,20}$ showed high sensitivity, but low specificity. In contrast, the results of this study showed the commercial extract had only $70.8 \%$ sensitivity, but very high specificity. Discrepancies among the results of these studies may be due to differences in ethnicity/race. For in-house Coca-10\% EtOH extract, we found that it yielded higher (91.7\%) sensitivity and better (86.7\%) accuracy than the commercial extract. The better results achieved by in-house Coca-10\% EtOH extract were likely due to the fact that $10 \% \mathrm{EtOH}$ is able to dissolve a high amount of gliadin and gluten. This result corresponds with our previous immunoblot study showed that the Coca-10\% EtOH extract had stronger IgE binding than the commercial extract. $^{13}$

Values of wheat-specific IgE have been used for diagnosis of wheat hypersensitivity in many studies. ${ }^{17,21}$ They showed high sensitivity, but had low specificity. ${ }^{7,20,21}$ It has been suggested that the value of specific IgE bound $\omega-5$ gliadin is a highly predictive value of immediate allergy to ingested wheat in children. ${ }^{10,22}$ However, our study found that, at $0.35 \mathrm{kAU} / \mathrm{L}$, the value of specific IgE bound $\omega-5$ gliadin yielded $76.7 \%$ accuracy, while the value of specific IgE bound allergens in ALK wheat extract yield $90 \%$ accuracy. This suggests that $\omega-5$ gliadin may not be the only major allergen in these cases. Our recent study in patients with wheat-induced anaphylaxis showed that their serum IgE bound not only to the alcohol-soluble allergens, but also to the water/salt soluble allergens. ${ }^{13}$ Therefore, SPT using in-house $10 \% \mathrm{EtOH}$ extract may be a better choice than quantitating specific IgE against only $\omega-5$ gliadin for diagnosis of wheat hypersensitivity. This diagnostic strategy has both lower cost and better sensitivity.

Interestingly and based on the results of skin prick test and specific IgE only Coca-10\% EtOH extract and sIgE for $\omega-5$ gliadin could discriminate patients who had positive OWC from patients who had anaphylaxis. Patients who have large size of SPT to Coca-10\% EtOH extract or have high level of sIgE for $\omega-5$ gliadin should avoid the OFC due to a higher risk of anaphylaxis. However, the sIgE method is more expensive than the SPT, our preliminary results suggest that Coca-10\% $\mathrm{EtOH}$ extract may be effective in screening patients for wheat anaphylaxis. However, a large cohort would be needed to confirm this hypothesis.

This is the first study to evaluate the accuracy of in-house wheat extract by dissolving wheat in Coca-10\% EtOH. Skin prick test with in-house extract had good correlation with open challenge test and had higher sensitivity than commercial extract. 


\section{Acknowledgements}

The authors gratefully acknowledge Miss Julaporn Pooliam for assistance with statistical analysis.

\section{Conflict of interest declaration}

The authors hereby declare no personal or professional conflicts of interest regarding any aspect of this study.

\section{Funding disclosure}

This study was supported by a Siriraj Grant for Research Development, Faculty of Medicine Siriraj Hospital, Mahidol University Bangkok, Thailand.

\section{Author contributions}

PP wrote the manuscript. NS and NP collected the data and perform the OFC. OJ, NV, PV provided clinical care to the patients. SP performed the in vitro study. All authors read and approved the final manuscript for publication.

\section{References}

1. Imamura T, Kanagawa Y, Ebisawa M. A survey of patients with self-reported severe food allergies in Japan. Pediatr Allergy Immunol. 2008;19:270-4.

2. Chiang WC, Kidon MI, Liew WK, Goh A, Tang JP, Chay OM. The changing face of food hypersensitivity in an Asian community. Clin Exp Allergy. 2007; 37:1055-61.

3. Liu AH, Jaramillo R, Sicherer SH, Wood RA, Bock SA, Burks AW, et al. National prevalence and risk factors for food allergy and relationship to asthma: results from the National Health and Nutrition Examination Survey 2005-2006. J Allergy Clin Immunol. 2010;126:798-806.

4. Zuidmeer L, Goldhahn K, Rona RJ, Gislason D, Madsen C, Summers C, et al. The prevalence of plant food allergies: a systematic review. J Allergy Clin Immunol. 2008;121:1210-8.

5. Jirapongsananuruk O, Bunsawansong W, Piyaphanee N, Visitsunthorn N, Thongngarm T, Vichyanond P. Features of patients with anaphylaxis admitted to a university hospital. Ann Allergy Asthma Immunol. 2007;98: 157-62.

6. Bahna SL. Food challenge procedure: optimal choices for clinical practice. Allergy Asthma Proc. 2007;28:640-6.

7. Palosuo K. Update on wheat hypersensitivity. Curr Opin Allergy Clin Immunol. 2003;3:205-9.
8. Inomata N. Wheat allergy. Curr Opin Allergy Clin Immunol. 2009;9: 238-43.

9. Matsuo H, Kohno K, Niihara H, Morita E. Specific IgE determination to epitope peptides of omega-5 gliadin and high molecular weight glutenin subunit is a useful tool for diagnosis of wheat-dependent exercise-induced anaphylaxis. J Immunol. 2005;175:8116-22.

10. Palosuo K, Varjonen E, Kekki OM, Klemola T, Kalkkinen N, Alenius H, et al. Wheat omega-5 gliadin is a major allergen in children with immediate allergy to ingested wheat. J Allergy Clin Immunol. 2001;108:634-8.

11. Ebisawa M, Shibata R, Sato S, Borres MP, Ito K. Clinical utility of IgE antibodies to omega-5 gliadin in the diagnosis of wheat allergy: a pediatric multicenter challenge study. Int Arch Allergy Immunol. 2012;158:71-6.

12. Ito K, Futamura M, Borres MP, Takaoka Y, Dahlstrom J, Sakamoto T, et al IgE antibodies to omega-5 gliadin associate with immediate symptoms on oral wheat challenge in Japanese children. Allergy. 2008;63:1536-42.

13. Pacharn P, Kumjim S, Tattiyapong P, Jirapongsananuruk O, Piboonpocanun $\mathrm{S}$. Identification of wheat sensitization using an in-house wheat extract in Coca-10\% alcohol solution in children with wheat anaphylaxis. Asian Pac J Allergy Immunol. 2016;34:153-8.

14. Sampson HA, Munoz-Furlong A, Campbell RL, Adkinson NF, Jr., Bock SA, Branum A, et al. Second symposium on the definition and management of anaphylaxis: summary report--second National Institute of Allergy and Infectious Disease/Food Allergy and Anaphylaxis Network symposium. Ann Emerg Med. 2006;47:373-80.

15. Dreborg S. Diagnosis of food allergy: tests in vivo and in vitro. Pediatr Allergy Immunol. 2001;12 Suppl 14:24-30.

16. Ventura A, Salvatore CM, Longo G. Might laboratory tests other than RAST help in diagnosing food allergy? Pediatr Allergy Immunol. 1995;6 Suppl 8:44-8.

17. Soares-Weiser K, Takwoingi Y, Panesar SS, Muraro A, Werfel T, Hoffmann -Sommergruber $\mathrm{K}$, et al. The diagnosis of food allergy: a systematic review and meta-analysis. Allergy. 2014;69:76-86.

18. Makela MJ, Eriksson C, Kotaniemi-Syrjanen A, Palosuo K, Marsh J, Borres $\mathrm{M}$, et al. Wheat allergy in children - new tools for diagnostics. Clin Exp Allergy. 2014;44:1420-30.

19. Eigenmann PA, Sampson HA. Interpreting skin prick tests in the evaluation of food allergy in children. Pediatr Allergy Immunol. 1998;9:186-91.

20. Sampson HA, Ho DG. Relationship between food-specific IgE concentrations and the risk of positive food challenges in children and adolescents. J Allergy Clin Immunol. 1997;100:444-51.

21. Nilsson N, Sjolander S, Baar A, Berthold M, Pahr S, Vrtala S, et al. Wheat allergy in children evaluated with challenge and $\operatorname{IgE}$ antibodies to wheat components. Pediatr Allergy Immunol. 2015;26:119-25.

22. Daengsuwan T, Palosuo K, Phankingthongkum S, Visitsunthorn N, Jirapongsananuruk $\mathrm{O}$, Alenius $\mathrm{H}$, et al. IgE antibodies to omega-5 gliadin in children with wheat-induced anaphylaxis. Allergy. 2005;60:506-9. 